\title{
Cannabinoids in Autism and Fragile X Syndrome: Value-Based Treatment Revolution Ahead?
}

\author{
Zoran M Pavlovic* \\ Independent CNS Consultant and CEO Neuroscience and Mental Health Services, Serbia \\ Submission: August 28, 2017; Published: September 08, 2017
}

*Corresponding author: Zoran M Pavlovic, Independent CNS Consultant and CEO Neuroscience and Mental Health Services, Miloja Djaka 15b, 11040 Belgrade, Serbia, Tel: +381603451967, Email: zoran.m.pavlovicmd@gmail.com

\section{Introduction}

Cannabis has a long history in Central and South Asia, as it was used to produce hemp fibre for rope, clothing and paper, but was also consumed both for recreational and medicinal purposes. The two major neuro active components in cannabis are the psychoactive $\Delta$ 9-tetrahydro-cannabinol $(\Delta 9$-THC) and the non-psychoactive cannabidiol (CBD). Recent years have seen a resurgence in interest in the therapeutic potential of compounds derived from cannabis, due to significant advances in our understanding of cannabis ingredients and endogenous brain cannabinoid (ECB) system, which consists of G-proteincoupled cannabinoid (CB) receptors, endocannabinoids such as N-Arachidonoylethanolamide (Anandamide) and 2-Arachidonoylglycerol (2-AG), synthetic and degradative enzymes, and transporters.

Common medical conditions for which marijuana is allowed in the US (i.e., those conditions shared by at least 80 percent of medical marijuana states) are: Alzheimer's disease, Amyotrophic Lateral Sclerosis, cachexia/wasting syndrome, cancer, Crohn's disease, epilepsy and seizures, glaucoma, hepatitis $\mathrm{C}$ virus,

human immunodeficiency virus/acquired immunodeficiency syndrome, Multiple Sclerosis and muscle spasticity, severe and chronic pain, severe nausea and Post-Traumatic Stress Disorder [1]. The advances in our understanding of exogenous cannabinoids actions and the physiology of ECB system, have led to important new insights, which are likely to result in the development of novel therapeutic strategies forkey CNS disorders.

\section{Autism}

Autismis characterized by deficits in communication and social interaction, as well as by stereotypic behaviors, restricted patterns of interest, and abnormal sensory issues [2]. Frequently, comorbid conditions include intellectual disability (65\%), seizures (30\%), and different forms of sleepproblems $[3,4]$.
Two of the most prominent features of autism are abnormal brain neuron organization [5] and immune system dysregulation $[6,7]$. During foetal life, CB1 receptors and their associated ECBs are important for neuron differentiation and proper axonal migration [8].

Modulation of CB1 receptors could trigger autism by interrupting normal brain development, as they are particularly abundant in forebrain sub-ventricular zones and cortical structures, which play a key role in cell proliferation and migration, respectively. They are also transiently located in forebrain white matter structures, which are essential for cell migration and axonal elongation during brain development $[9,10]$. In contrast to CB1 receptors, CB2 receptors were primarily detected in immune cells and at too much lesser extent in the brain, where they are acting as immunomodulators.

Neuro inflammation is a frequent finding in autistic individuals and include differential monocyte responses, abnormal T-helper cytokine levels, decreased T-cell mitogen response, decreased numbers of lymphocytes, abnormal serum immunoglobulin levels. antibodies against central nervous system and maternal proteins [11]. If we postulate that autism is neuro-immunological disorder, modulation of CB1 and CB2 receptors signaling could offer one of the promising therapeutic options.

ECB signaling and social interaction processing systems: Initial stages of social interaction require overcoming, negative valence systems (e.g. fear, anxiety), in order to initiate the interaction and are reinforced by positive valence systems (e.g. reward learning, reward valuation). Cognitive systems (i.e. attention, perception, working memory) then guide the exchange after social interaction has commenced, while social process systems (i.e. affiliation and attachment, social communication, perception of self and others) exert supramodal control to coordinate germane practices. Dysfunction in one 
construct intrinsically affects social information processing and impacts the ability to function typically. Role of cannabis in modulating social interactions was first observed by French psychiatrist Dr. Jacques Moreau de Tours in $19^{\text {th }}$ century. Dr Moreau noted similarities between experiences in healthy humans after ingesting North African hashish (which contains very high concentration of THC), and dysfunctions in his patients that he called 'neurological dysregulation' and 'social alienation' [12]. He described these symptoms as fluctuations of emotions (i.e. negative valence), extreme happiness and excitement (i.e. positive valence), errors of time and space, illusions and hallucinations (arousal/regulatory) and irresistible impulses and dissociation of ideas (i.e. cognitive domain) [13]. Human studies have shown that marijuana heightens the saliency of social interactions [14], enhances interpersonal communication [15], and decreases hostile feelings within small social groups [16]. The neural mechanisms underlying these prosocial effects are unclear but are likely to involve activation of CB1 receptors, the main molecular target of marijuana in the human brain. Consistent with this idea, CB1 receptors are highly expressed in associational cortical regions of the frontal lobe, but also in subcortical structures involved in social-emotional functioning $[17,18]$. Moreover, the receptors and their endogenous lipid-derived ligands, anandamide and 2-AG [19], have been implicated in the control of social play [20] and social anxiety [21] in laboratory animals, which are two crucial aspects of animal social experience. Plausible explanation of all these effects, is that oxytocin, which has primary physiological function to heighten the saliency of social stimuli, triggers an anandamide-mediated signal in the nucleus accumbens (NAc), thus influencing synaptic plasticity via activation of local CB1 receptors. Other modulatory neurotransmitters may also play a role in regulating the interaction between oxytocin and anandamide, such as serotoninwhich is needed for the expression of oxytocin-dependent plasticity in the NAc [22], and dopamine which has been implicated in striatal anandamide signaling [23]. Additional hypothesis is that some of social behavioral deficits in autism arise dueto deficits in reward system functioning $[24,25]$. This is supported by studies that report a lack of social motivationin children with autism, who do not find social stimuli rewarding and hence do not attend to them as much as normal children [26,27]. An alternative formulation of the social motivationhypothesissuggests that the attention of individuals with andwithout autism is drawn to social stimuli to a comparable extent,but individuals with autism find social stimuli less rewarding [28,29].

All scientific research findings mentioned above suggest that ECB system is involved in regulation of at least three key features known to be atypical in autism:

i. Neural development.

ii. Immunological system modulation and

iii. Social interaction/reward responsivity.
Further research of this system is necessary, to develop valid and reliable diagnostic biomarkers and specific therapeutic interventions.

\section{Fragile X syndrome}

Fragile X syndrome (FXS) is a neuro developmental disorder characterized by cognitive impairment, attention deficit, hyperactivity, anxiety, unstable mood, autistic behaviors, language delay and seizures [30]. This X-linked chromosome disorder is the most common known cause of autism with $30 \%$ of boys meeting full autism criteria [31]. FXS is caused by a trinucleotide repeat expansion (CGG) in the FMR1gene, which results in the loss of expression of fragile X-mental retardation protein (FMRP) [32], an RNA binding protein that negatively regulates synaptic protein synthesis [33]. Recent advances in FMR1 allele analysis, allow rapid and inexpensive assessment of CGG repeat size, the number of AGG interruptions and methylation status from blood or saliva samples [34].

This FMR1 DNA test is currently used for detection of Fragile $\mathrm{X}$ carriers and early diagnosis of FXS. In research settings animal model used to mimic FXS in humans is the FMR1 knockout mice, where knockout of FMR1 gene removes FMRP [35]. It was shown that mutations in this gene are linked to enhancement of mGluR GpI signaling, especially at mGluR5, and lead to altered synaptic plasticity in FXS [36]. Possible interpretation of this finding, is that activation of metabotropic glutamate receptor (mGluR) Group I (GpI) i.e. mGluR1 and mGluR5, enhances FMRP synthesis [37], while its absence results in a loss of translational controland enhancement of cerebral and mGluR protein synthesis. This interconnection supported the development of "mGluRtheory of fragileX", published in 2004., that identifies FMRP as a key downstream regulator of mGluR activation (specifically mGluR5) [37].

The theory in line with current scientific knowledge about cross-talk between glutamatergic and ECB system, which acts as an neuromodulatory system that fine-tunes excitatory glutamatergic synaptic transmission [38]. This fine control is obtained through CB1 receptors which are profusely expressed in presynaptic terminals of glutamatergic cells [39], where they preclude release of glutamate upon stimulation by ECBs. Maejima et al. [40] have confirmed that heightened postsynaptic activation of mGluR5 inFMR1knockout mice, increased Gp1 mGluR dependent ECB mobilization (synthesis and release), anddesensitizedCB1 receptors which led to increased propensity for uncontrolled neuronal firing.

Unfortunately, results from animal models did not translate to humans with FXS, as targeted stimulation of mGluR5 did not lead to symptom improvement [41]. Since then the focus shifted to GABA and the hypothesis that decreased GABA transmission in cerebral cortex underlies FXS pathophysiology. GABA ergic neurotransmission is also modulated by ECB system, especially by CB1 receptors, which are 10-20 times more expressed in 
inhibitory than in excitatory terminals,in specific brain regions such as hippocampus andcerebellar cortex [42], Therefore targeting disturbed GABAergic neurotransmission via CB1 receptors, might represent a novel concept in development of effective treatment options for FXS.

Future studies especially in human population are needed for better understanding of interactions between FMRP and ECB system, as these would pave the way for development of FXS specific biomarkers and treatment interventions.

\section{Conclusion}

Although basic research and preclinical data support the use of exogenous cannabinoids THC and CBD in neuro developmental disorders such as Autism, Fragile X Syndrome and other Autism Spectrum Disorders. double blind placebo controlled trials are urgently needed to establish efficacy, safety and extent of benefit on the quality of life of all endocannabinoid-mimetic compounds.

vast numbers of siblings, only two of which need to survive to reproduce and continue the genetic line.

Thus, nurture (learning) reigns among anthropoids and nature (genetics) at the other extreme where simple instinctive patterns of behavior suffice for survival of the species.

\section{References}

1. Belendiuk KA, Baldini LL, Bonn-Miller MO (2015) Narrative review of the safety and efficacy ofmarijuana for the treatment of commonly stateapproved medical and psychiatric disorders. Addict Sci Clin Pract 10: $1-9$.

2. Arlington VA (2013) Diagnostic and statistical manual of mental disorders. $\left(5^{\text {th }}\right.$ Edn), American Psychiatric Association, USA.

3. Tuchman R, Rapin I (2002) Epilepsy in autism. Lancet Neurol 1(6): 352-358.

4. Souders MC, Mason TB, Valladares O, Bucan M, Levy SE, et al. (2009) Sleep behaviors and sleep quality in children with autism spectrum disorders. Sleep 32(12): 1566-1578.

5. Courchesne E, Pierce K, Schumann CM, Redcay E, Buckwalter JA, et al (2007) Mapping early brain development in autism. Neuron 56(2): 399-413.

6. Pessah IN, Seegal RF, Lein PJ, LaSalle J, Yee BK, et al. (2008) Immunologic and neurodevelopmentalsusceptibilities of autism. Neurotoxicology 29(3): 532-545.

7. Vargas DL, Nascimbene C, Krishnan C, Zimmerman AW, Pardo CA (2005) Neuroglial activation and neuroinflammation in the brain ofpatients with autism. Ann Neurol 57(1): 67-81.

8. Fride E, Gobshtis N, Dahan H, Weller A, Giuffrida A, et al. (2009) The endocannabinoid system during development: emphasis on Perinatal events and delayed effects. Vitam Horm 81: 139-158.

9. Fernández-Ruiz J, Berrendero F, Hernández ML, Ramos JA (2000) The endogenous cannabinoidsystem and brain development. Trends Neurosci 23(1): 14-20.

10. Romero J, García-Palomero E, Berrendero F, García-Gil L, Hernández ML, et al. (1997) Atypical location of cannabinoid receptors in white matter areas during rat brain development. Synapse 26(3): 317-323.

11. Ashwood P, Wills S, van de Water J (2006) The immune response in autism: A new frontier for autism research. J Leukoc Biol 80(1): 1-15.

12. Moreau de Tours JJ (1845) Du hachisch et de l'aliénation mentale : études psychologiques. Fortin Masson (Ed.), Paris, France.

13. Moreau de Tours JJ (1973) Hashish and Mental Illness. Raven Press, New York, USA.

14. Tart CT (1970) Marijuana intoxication common experiences. Nature 226(5247): 701-704.

15. Salzman C, Kochansky GE, Van Der Kolk BA, Shader RI (1977) The effect of marijuanaon small group process. Am J Drug Alcohol Abuse 4(2): 251-255.

16. Salzman C, Van Der Kolk BA, Shader RI (1976) Marijuana and hostility in a small-groupsetting. Am J Psychiatry 133(9): 1029-1033.

17. Glass M, Dragunow M, Faull RL (1997) Cannabinoid receptors in the human brain: Adetailed anatomical and quantitative autoradiographic study in the fetal, neonataland adult human brain. Neuroscience 77(2): 299-318.

18. Seeley WW, Zhou J, Kim E-J (2012) Frontotemporal dementia: What can the behavioural variant teach us about human brain organization? Neuroscientist 18(4): 373-385.

19. Piomelli D (2014) More surprises lying ahead. The endocannabinoids keep us guessing. Neuropharmacology 76(Pt B): 228-234.

20. Trezza V, Damsteegt R, Manduca A, Petrosino S, Van Kerkhof LW, et al. (2012) Endocannabinoids in amygdala and nucleus accumbens mediatesocial play reward in adolescent rats. J Neurosci 32(43):1489914908.

21. Bergamaschi MM, Queiroz RH, Chagas MH, Linares IM, Ila M. P. Linares, Arrais KC, et al. (2014) Rimonabant effects on anxiety induced by simulated public speaking in healthy humans: A preliminary report. Hum Psychopharmacol 29(1): 94-99.

22. Dölen G, Darvishzadeh A, Huang KW, Malenka RC (2013) Social reward requires coordinatedactivity of nucleus accumbens oxytocin and serotonin. Nature 501(7466): 179-184.

23. Giuffrida A, Parsons LH, Kerr TM, Rodríguez de Fonseca F, Navarro M, et al. (1999) Dopamine activation of endogenous cannabinoid signalling in dorsal striatum. Nat Neurosci 2(4): 358-363.

24. Chevallier C, Kohls G, Troiani V, Brodkin ES, Schultz RT (2012) The social motivation theory of autism. Trends Cogn Sci 16(4): 231-239.

25. Sims TB, Neufeld J, Johnstone T, Chakrabarti B (2014) Autistic traits modulate frontostriatal connectivity during processing of rewarding faces. Soc Cogn Affect Neurosci 9(12): 2010-2016.

26. Dawson G, Carver L, Meltzoff AN, Panagiotides H, McPartland J, et al. (2002) Neural correlates of face and object recognition in young children with autism spectrum disorder, developmental delay, and typicaldevelopment. Child Dev 73(3):700-717.

27. Pierce K, ConantD, Hazin R, Stoner R, Desmond J (2011) Preference forgeometric patterns early in life as a risk factor for autism. ArchGen Psychiatry 68(1): 101-109.

28. Stavropoulos KK, Carver LJ (2014) Effect of familiarity on reward anticipation in children with and without autism spectrum disorders. PLoS One 9(9): e106667.

29. Richey JA, Rittenberg A, Hughes L, Damiano CR, Sabatino A, et al. (2014) Common and distinct neural features of social and non-social reward processing in autism and social anxiety disorder. Soc Cogn Affect Neurosci 9(3): 367-377.

30. Hagerman R, Hoem G, Hagerman P (2010) Fragile X and autism: intertwined at the molecular level leading to targeted treatments. Mol Autism 1(1): 12. 
31. Harris SW, Hessl D, Goodlin-Jones B, Ferranti J, Bacalman S, et al. (2008) Autism profiles of males with fragile X syndrome. Am J MentRetard 113(6): 427-438.

32. Santoro MR, Bray SM, Warren ST (2011) Molecular mechanisms of Fragile X syndrome: a twenty-year perspective. Annu Rev Pathol 7: 219-245.

33. Brown V, Jin P, Ceman S, Darnell JC, O'Donnell WT, et al. (2001) Microarray identification of FMRP-associated brain mRNAs and altered mRNA translational profiles in fragile X syndrome. Cell 107(4): 477487.

34. Hayward BE, Zhou Y, Kumari D, Usdin K (2016) A set of assays for the comprehensive analysis of fMR1 alleles in the Fragile X-related disorders. J Mol Diagn 18(5): 762-774.

35. Weiler IJ, GreenoughWT (1999) Synaptic synthesis of the fragile X protein: possible involvement in synapse maturation and elimination. Am J Med Genet 83(4): 248-252.

36. O'Donnell WT, Warren ST (2002) Adecade of molecular studies of fragileX syndrome. Annu Rev Neurosci 25: 315-338.
37. Bear MF, Huber KM, Warren ST (2004) The mGluR theory of fragile X mental retardation. TrendsNeurosci 27(7): 370 -377.

38. Marsicano G, Lutz B (1999) Expression of the cannabinoid receptor CB1 in distinct neuronal subpopulations in the adult mouse forebrain. Eur J Neurosci 11(12): 4213-4225.

39. Varma N, Carlson GC, Ledent C, Alger BE (2001) Metabotropic glutamate receptors drive the endocannabinoidsystem in hippocampus. J. Neurosci 21(24): RC188.

40. Maejima T, Hashimoto K, Yoshida T, Aiba A, Kano M (2001) Presynaptic inhibition caused by retrograde signal from metabotropic glutamate to cannabinoid receptors. Neuron 31(3): 463-475.

41. Scharf SH, Jaeschke G, Wettstein JG, Lindeman L (2015) Metabotropic glutamate receptor 5 as drug target for Fragile X syndrome. Curr Opin Pharmacol 20: 124-134.

42. Kawamura Y, Fukaya M, Maejima T, Yoshida T, Miura E, et al. (2006) The CB1 cannabinoid receptor is the major cannabinoid receptor at excitatory presynaptic sites in the hippocampus and cerebellum. J Neurosci 26(11): 2991-3001. 